
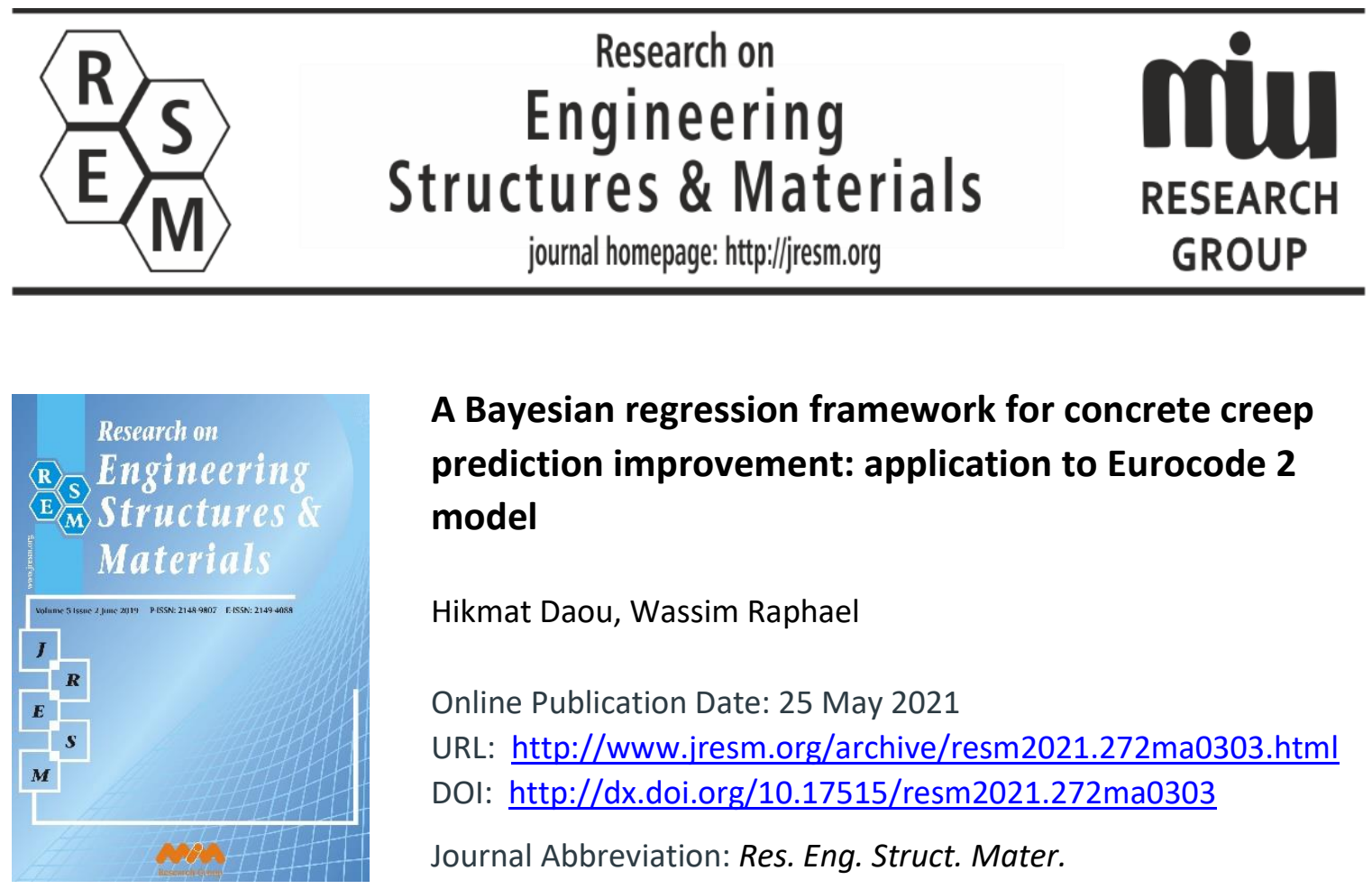

\title{
A Bayesian regression framework for concrete creep prediction improvement: application to Eurocode 2 model
}

Hikmat Daou, Wassim Raphael

Online Publication Date: 25 May 2021

URL: http://www.jresm.org/archive/resm2021.272ma0303.html

DOI: http://dx.doi.org/10.17515/resm2021.272ma0303

Journal Abbreviation: Res. Eng. Struct. Mater.

\section{To cite this article}

Daou H, Raphael W. A Bayesian regression framework for concrete creep prediction improvement: application to Eurocode 2 model. Res. Eng. Struct. Mater., 2021; 7(3393-411.

\section{Disclaimer}

All the opinions and statements expressed in the papers are on the responsibility of author(s) and are not to be regarded as those of the journal of Research on Engineering Structures and Materials (RESM) organization or related parties. The publishers make no warranty, explicit or implied, or make any representation with respect to the contents of any article will be complete or accurate or up to date. The accuracy of any instructions, equations, or other information should be independently verified. The publisher and related parties shall not be liable for any loss, actions, claims, proceedings, demand or costs or damages whatsoever or howsoever caused arising directly or indirectly in connection with use of the information given in the journal or related means.

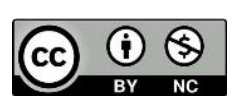

Published articles are freely available to users under the terms of Creative Commons Attribution - NonCommercial 4.0 International Public License, as currently displayed at here (the "CC BY - NC"). 


\title{
Research on Engineering Structures \& Materials
}

journal homepage: http://jresm.org

Research Article

\section{A Bayesian regression framework for concrete creep prediction improvement: application to Eurocode 2 model}

\author{
Hikmat Daou*a, Wassim Raphael ${ }^{\text {b }}$ \\ Ecole Supérieure d'Ingénieurs de Beyrouth (ESIB), Saint-Joseph University, Lebanon
}

\begin{tabular}{|c|c|}
\hline Article Info & Abstract \\
\hline $\begin{array}{l}\text { Article history: } \\
\text { Received 03 Mar } 2021 \\
\text { Revised 04 May } 2021 \\
\text { Accepted } 15 \text { May } 2021\end{array}$ & $\begin{array}{l}\text { Concrete is the most widely used material in the construction industry due to its } \\
\text { strength, workability and durability. But under a sustained load, concrete is } \\
\text { prone to creep causing excessive long-term deflection of structural members, } \\
\text { cracks in tensile members, redistribution of stresses over time in composite } \\
\text { structures, and loss of prestressing force in prestressed concrete elements. }\end{array}$ \\
\hline $\begin{array}{l}\text { Keywords: } \\
\text { Creep; } \\
\text { Concrete; } \\
\text { Eurocode 2; } \\
\text { Bayesian linear } \\
\text { regression }\end{array}$ & $\begin{array}{l}\text { Therefore, structural engineers must accurately predict the concrete creep over } \\
\text { the long-term. The concrete creep coefficient is an important entry in many } \\
\text { calculations and analyses of reinforced concrete structures. Currently, many } \\
\text { models such as the Eurocode } 2 \text { model have predicted the concrete creep } \\
\text { coefficient. Based on a large database for creep tests, this study aims to improve } \\
\text { the prediction of the Eurocode } 2 \text { creep coefficient model at long-term by } \\
\text { implementing correction coefficients into the model. Since Bayesian-type } \\
\text { inferences are suitable tools for revising and updating design codes, the } \\
\text { correction coefficients are calculated based on Bayesian linear regression. } \\
\text { Statistical indicators demonstrate the accuracy and effectiveness of the } \\
\text { proposed improvement and modification. }\end{array}$ \\
\hline
\end{tabular}

(C) 2021 MIM Research Group. All rights reserved.

\section{Introduction}

Concrete is a composite material consisting of a mortar phase and aggregates and is known as a brittle material having low tensile strength and tensile strain capacity. For that, concrete is usually reinforced using different materials such as steel or fiber [1]. In literature, reinforced concrete structures are continually studied as being one of the world's most common building materials in the construction industry [2-4].

When concrete is subjected to long-term stresses, it is prone to creep. In other words, creep is the time-dependent movement or deformation of concrete. Indeed, creep can affect structural behavior by violating the service limit states, by losing the prestressing forces, or by redistributing the stress [5-9]. Therefore, creep is of great practical importance to structural engineers, and thus, it has been studied by many researchers [10-17]. Hence, designers must accurately predict creep strains using precise methods.

There are many sophisticated and practical models for predicting creep [18-22]. The Eurocode 2 model [19] is one of the most widely used models for predicting shrinkage and creep. Based on a large experimental database, the EC2 shrinkage model has been updated [23], and correction coefficients have also been proposed for the Eurocode 2 creep model [24] but the calculation of these correction coefficients are limited for a specific condition of initial time loading, relative humidity, or compressive strength. For that, it is necessary to improve the creep coefficient prediction by taking into consideration the different concrete mix compositions and the various environmental conditions. 
In order to optimize and improve a model, many optimization models have been developed in the literature [25-27]. Frequentist inference and Bayesian inference are two types of statistical inference. Frequentist ordinary least squares (OLS) regression models are perceived to handle large data sets and are easy to perform while Bayesian linear regression (BLR) models have been traditionally restricted to small sample sizes and have many things need to be specified such as prior distributions, initial values for numerical approximation, and the likelihood function. On the other hand, Bayesian inference allows informative priors where the prior knowledge or results of a previous model can be used to inform the current model and can avoid problems with model identification by manipulating prior distributions, especially in complex models. BLR model also delivers the answer to the right question in the sense that Bayesian inference provides answer to conditional on the observed data and not based on the distribution of estimators or test statistics over imaginary samples not observed [28]. Moreover, Bayesian inference has a decision theoretic foundation [29,30]. The purpose of most statistical inference is to facilitate decision-making, and the Bayesian decision is the optimal decision. Bayesian inference has been used in different civil engineering problems [31-34]. In addition, Bayesian inference is also an appropriate tool for revising and updating design codes; therefore, BLR is used in this study.

This study aims is to evaluate the long-term Eurocode 2 creep coefficient model and improve it by implementing correction coefficients to the model using Bayesian linear regression for different concrete mix compositions and under various environmental conditions.

\section{Database and Methods}

\subsection{Northwestern University Database}

During the period 2010-2013, a large database was assembled at Northwestern University (NU), mainly under the support of the U.S. Department of Transportation [24]. This NU database is based on information extracted from numerous reports, journal articles, and conference proceedings. The tests of this database are performed using different concrete mix compositions and under various environmental conditions such as aggregate-cement ratio $(\mathrm{a} / \mathrm{c})$, water-cement ratio $(\mathrm{w} / \mathrm{c})$, concrete compressive strength $\left(\mathrm{f}_{\mathrm{cm}}\right)$, cement type, effective thickness $\left(\mathrm{h}_{0}\right)$, loading age $\left(\mathrm{t}_{0}\right)$, sustained stress over the compressive strength at loading age $\sigma / \mathrm{f}_{\mathrm{cm}(\mathrm{to})}$, temperature $(\mathrm{T})$, relative humidity $(\mathrm{RH})$, etc.

\subsection{Eurocode 2 creep predictions}

The Eurocode 2 model (EC2) [15] predicts compliance according to Eq. (1). Compliance is defined as the total load-induced strain at age t per unit caused by a unit uniaxial sustained load applied since loading age $t_{0}[25]$.

$$
J\left(t, t_{0}\right)=\frac{1}{E_{c m t 0}}+\frac{\varphi_{28}\left(t, t_{0}\right)}{E_{c m 28}}
$$

where $E_{c m t 0}$ is the modulus of elasticity of concrete at the loading age $t_{0}(\mathrm{MPa}), \mathrm{E}_{\mathrm{cm} 28}$ is the mean modulus of elasticity at 28 days $(\mathrm{MPa})$, and $\varphi_{28}\left(\mathrm{t}, \mathrm{t}_{0}\right)$ is the dimensionless 28-day creep coefficient.

The creep coefficient, $\varphi_{28}\left(\mathrm{t}, \mathrm{t}_{0}\right)$, gives the ratio of the creep strain since the start of age loading $t_{0}$ to the elastic strain due to constant stress applied at a concrete age of 28 days. Fig. 1 represents the plot of the natural logarithm of the EC2 creep coefficient $\left(\ln \left(\varphi_{\mathrm{EC}} 2\right)\right)$ versus the natural logarithm of the creep coefficient obtained from the NU database $\left(\ln \left(\varphi_{\mathrm{NU}}\right)\right)$. In order to show the linearity between $\ln \left(\varphi_{\mathrm{EC} 2}\right)$ and $\ln \left(\varphi_{\mathrm{NU}}\right)$, a quadratic term model has been proposed to fit the relation between these two variables. The polynomial 
term for the second-order was not significant. Moreover, a comparison between the quadratic term model and the linear model was performed based on the Akaike information criterion (AIC) [35] and the results showed that the linear model is a good fit for the data. Therefore, the long-term creep coefficient is considered to be updated and calibrated based on the NU database by inserting correction coefficients, A and B, into the formula as shown in Eq. (2).

$$
\varphi_{u p d}\left(t, t_{0}\right)=A \times \varphi_{28}\left(t, t_{0}\right)^{B}
$$

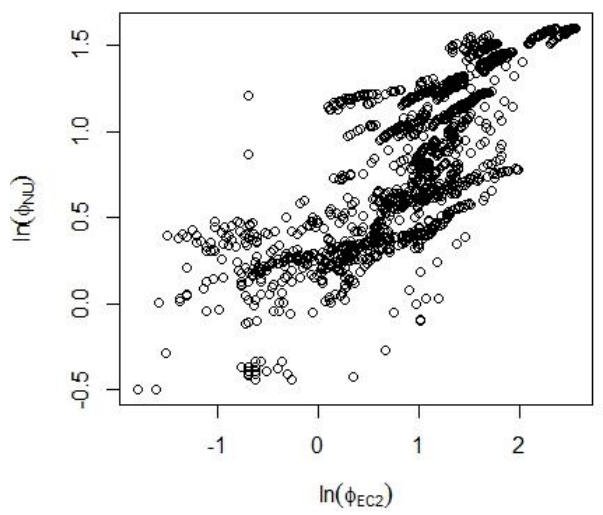

Fig. 1 Plot of the natural logarithm of the EC2 creep coefficient versus the natural logarithm of the actual creep coefficient

\subsection{Bayesian Linear Regression}

Bayesian statistics primarily involve conditional probability, which is the probability of an event $X$ given event $Y$, and it can be calculated using Bayes' rule (Eq. (3)).

$$
P(X \mid Y)=\frac{P(Y \mid X) \times P(X)}{P(Y)}
$$

where $\mathrm{X}$ and $\mathrm{Y}$ are events, $\mathrm{P}(\mathrm{X})$ and $\mathrm{P}(\mathrm{Y})$ are the marginal probabilities of event $\mathrm{X}$ and event $\mathrm{Y}$ occurring respectively, $\mathrm{P}(\mathrm{X} \mid \mathrm{Y})$ is the conditional probability that event $\mathrm{X}$ occurs given that event $\mathrm{Y}$ has already occurred, and $\mathrm{P}(\mathrm{Y} \mid \mathrm{X})$ is the conditional probability that event $\mathrm{Y}$ occurs given that event $\mathrm{X}$ has already occurred.

Bayesian inference uses Bayes' theorem to deduce properties on a population or a probability distribution from data (Eq. (4)).

$$
P(\Theta \mid \text { data })=\frac{P(\text { data } \mid \Theta) x P(\Theta)}{P(\text { data })}
$$

where $\Theta=\{\mu, \sigma\}$ represents the set of parameters of a Gaussian distribution where $\mu$ is the mean and $\sigma$ is the standard deviation, $\mathrm{P}(\Theta \mid$ data $)$ is the posterior distribution, $\mathrm{P}($ data $\mid \Theta)$ is the likelihood distribution, $\mathrm{P}(\Theta)$ is the prior distribution.

Bayesian Linear Regression (BLR) is an approach to linear regression in which statistical analysis is undertaken within the context of Bayesian inference. Therefore, linear regression is formulated using probability distributions rather than point estimates. To apply the BLR model, and since linearization does not affect the results, the logarithm of 
Eq. (2) is calculated, and the error $\in$ is considered in the calculations as shown in the following equation:

$$
\ln \left(\varphi_{u p d}\left(t, t_{0}\right)\right)=\ln (A)+B \times \ln \left(\varphi_{28}\left(t, t_{0}\right)\right)+\epsilon
$$

To calculate A and B, the updated creep coefficient is assumed to be the value obtained experimentally in the NU database.

Considering $\mathrm{y}=\ln \left(\varphi_{\text {upd }}\left(t, t_{0}\right)\right)$ and $x=\ln \left(\varphi_{28}\left(t, t_{0}\right)\right)$, Eq. (5) can be written as:

$$
y=A+B x+\epsilon
$$

The equation of the i-th observation can be written as:

$$
y_{i}=A+B x_{i}+\epsilon_{i}
$$

$\mathrm{y}$ is the response variable that corresponds to the $\mathrm{i}$-th experimental value; $\mathrm{x}$ is the predictor variable that relates to the value predicted by the EC2 equation, $\mathrm{A}$ is the y-intercept parameter, $\mathrm{B}$ is the slope parameter, and $\epsilon_{i}$ is the $\mathrm{i}$-th error.

\subsubsection{Likelihood distribution $\mathcal{L}\left(A, B, \sigma^{2}\right)$}

The error $\epsilon_{i}$ is assumed to be independent and identically distributed as normal random variables with zero mean and constant variance $\sigma^{2}$. Therefore, the random variable of each response $\mathrm{y}_{\mathrm{i}}$, conditioning on the observed data $\mathrm{x}_{\mathrm{i}}$ and the parameters $\mathrm{A}, \mathrm{B}$ and $\sigma^{2}$, is also normally distributed:

$$
y_{i} \mid x_{i}, A, B, \sigma^{2} \stackrel{i i d}{\sim} \operatorname{Normal}\left(A+B x_{i}, \sigma^{2}\right), \quad i=1, \ldots, n
$$

Thus, the likelihood of each $\mathrm{y}_{\mathrm{i}}$ given $\mathrm{x}_{\mathrm{i}}, \mathrm{A}, \mathrm{B}$, and $\sigma^{2}$ is given by:

$$
p\left(y_{i} \mid x_{i}, A, B, \sigma^{2}\right)=\frac{1}{\sqrt{2 \pi \sigma^{2}}} \exp \left(-\frac{\left(y_{i}-\left(A+B x_{i}\right)\right)^{2}}{2 \sigma^{2}}\right)
$$

The likelihood of $y 1, \ldots, y n$, denoted as $\mathcal{L}\left(A, B, \sigma^{2}\right)$, is the product of each likelihood $P\left(y_{i} \mid x_{i}, A, B, \sigma^{2}\right)$ since each response yi is independent from each other.

$$
p\left(y_{1}, \ldots, y_{n} \mid x_{i}, A, B, \sigma^{2}\right)=\prod_{i=1}^{n} P\left(y_{i} \mid x_{i}, A, B, \sigma^{2}\right)
$$

\subsubsection{Prior distribution}

Since no prior information is available, reference priors are used. The joint prior distribution of A, B under $\sigma^{2}$ is assumed to be a uniform prior, while the prior distribution of $\sigma^{2}$ proportional to the inverse of $\sigma^{2}$ [36]:

$$
\begin{aligned}
& p\left(A, B \mid \sigma^{2}\right) \propto 1 \\
& p\left(\sigma^{2}\right) \propto \frac{1}{\sigma^{2}}
\end{aligned}
$$

By combining these two conditional probabilities, the joint prior distribution obtained is:

$$
p\left(A, B, \sigma^{2}\right) \propto \frac{1}{\sigma^{2}}
$$




\subsubsection{Posterior distribution}

According to Eq. (4), the joint posterior distribution of A, B, and $\sigma^{2}$ is proportional to the product of the likelihood and the joint prior distribution.

$$
\begin{aligned}
& p\left(A, B, \sigma^{2} \mid y_{1}, \ldots, y_{n}\right) \propto \prod_{i=1}^{n} P\left(y_{i} \mid x_{i}, A, B, \sigma^{2}\right) p\left(A, B, \sigma^{2}\right) \\
& \propto\left[\left(\frac{1}{\sqrt{\sigma^{2}}} \exp \left(-\frac{\left(y_{1}-\left(A+B x_{1}\right)\right)^{2}}{2 \sigma^{2}}\right)\right) \times \ldots \times\right. \\
& \left.\left(\frac{1}{\sqrt{\sigma^{2}}} \exp \left(-\frac{\left(y_{n}-\left(A+B x_{n}\right)\right)^{2}}{2 \sigma^{2}}\right)\right)\right] \times\left(\frac{1}{\sigma^{2}}\right) \\
& \propto \frac{1}{\left(\sigma^{2}\right)^{(n+2) / 2}} \exp \left(-\frac{\sum_{i=1}^{n}\left(y_{i}-\left(A+B x_{i}\right)\right)^{2}}{2 \sigma^{2}}\right)
\end{aligned}
$$

Considering $S_{x x}=\sum_{i=1}^{n}\left(x_{i}-\bar{x}\right)^{2}, S_{y y}=\sum_{i=1}^{n}\left(y_{i}-\bar{y}\right)^{2}, S_{x y}=\sum_{i=1}^{n}\left(x_{i}-\bar{x}\right)\left(y_{i}-\bar{y}\right), S S E=$ $\sum_{i=1}^{n} \widehat{\epsilon}_{l}{ }^{2}, \hat{B}=\frac{s_{x y}}{s_{x x}}, \hat{A}=\bar{y}-\frac{s_{x y}}{s_{x x}} \bar{x}$, and $\widehat{\sigma}^{2}=\frac{S S E}{n-2}$ where $\bar{y}$ and $\bar{x}$ are the average of $\mathrm{y}$ and $\mathrm{x}$, respectively, and $\mathrm{n}$ is the number of observations, and after making some calculations and simplifications, the posterior joint distribution of $A, B, \sigma^{2}$ can be simplified as:

$$
\begin{aligned}
& p\left(A, B, \sigma^{2} \mid y_{1}, \ldots, y_{n}\right) \propto \\
& \frac{1}{\left(\sigma^{2}\right)^{\frac{n+2}{2}}} \exp \left(-\frac{S S E+n[(A-\widehat{A})+(B-\hat{B}) \bar{x}]^{2}+(B-\widehat{B})^{2} S_{x x}}{2 \sigma^{2}}\right)
\end{aligned}
$$

\subsubsection{Marginal Posterior Distribution of B}

The marginal posterior distribution of B is obtained by integrating $A$ and $\sigma^{2}$ out from the joint posterior distribution.

$$
\begin{aligned}
& p\left(B \mid y_{1}, \ldots, y_{n}\right)=\int_{0}^{\infty}\left(\int_{-\infty}^{\infty} P\left(A, B, \sigma^{2} \mid y_{1}, \ldots, y_{n}\right) d A\right) d \sigma^{2} \\
& = \\
& \int_{0}^{\infty}\left(\int_{-\infty}^{\infty} \frac{1}{\left(\sigma^{2}\right)^{\frac{n+2}{2}}} \exp \left(-\frac{S S E+n[(A-\hat{A})+(B-\hat{B}) \bar{x}]^{2}+(B-\hat{B})^{2} S_{x x}}{2 \sigma^{2}}\right) d A\right) d \sigma^{2} \\
& \quad=\int_{0}^{\infty} p\left(B, \sigma^{2} \mid y_{1}, \ldots, y_{n}\right) d \sigma^{2} \\
& p\left(B, \sigma^{2} \mid y_{1}, \ldots, y_{n}\right)= \\
& \int_{-\infty}^{\infty} \frac{1}{\left(\sigma^{2}\right)^{\frac{n+2}{2}}} \exp \left(-\frac{S S E+n[(A-\hat{A})+(B-\hat{B}) \bar{x}]^{2}+(B-\hat{B})^{2} S_{x x}}{2 \sigma^{2}}\right) d A \\
& \frac{1}{\left(\sigma^{2}\right)^{\frac{n+2}{2}}} \exp \left(-\frac{S S E+(B-\hat{B})^{2} \sum_{i=1}^{n}\left(x_{i}-\bar{x}\right)^{2}}{2 \sigma^{2}}\right) \int_{-\infty}^{\infty} \exp \left(-\frac{n[A-\hat{A}+(B-\hat{B}) \bar{x}]^{2}}{2 \sigma^{2}}\right) d A
\end{aligned}
$$




$$
\propto \frac{1}{\left(\sigma^{2}\right)^{\frac{n+1}{2}}} \exp \left(-\frac{S S E+(B-\hat{B})^{2} \sum_{i=1}^{n}\left(x_{i}-\bar{x}\right)^{2}}{2 \sigma^{2}}\right)
$$

Considering $\emptyset=\frac{1}{\sigma^{2}}$

$$
\begin{aligned}
& p\left(B \mid y_{1}, \ldots, y_{n}\right)=\int_{0}^{\infty} \frac{1}{\left(\sigma^{2}\right)^{\frac{n+1}{2}}} \exp \left(-\frac{S S E+(B-\hat{B})^{2} \sum_{i=1}^{n}\left(x_{i}-\bar{x}\right)^{2}}{2 \sigma^{2}}\right) d \sigma^{2} \\
& =\int_{0}^{\infty} \emptyset^{\frac{n-3}{2}} \exp \left(-\frac{S S E+(B-\hat{B})^{2} \sum_{i=1}^{n}\left(x_{i}-\bar{x}\right)^{2}}{2 \emptyset}\right) d \emptyset= \\
& \int_{0}^{\infty} p\left(B, \emptyset \mid y_{1}, \ldots, y_{n}\right) d \emptyset
\end{aligned}
$$

After integrating Eq. (17), the following equation is obtained:

$$
p\left(B \mid y_{1}, \ldots, y_{n}\right) \propto\left(1+\frac{1}{n-2} \times \frac{(B-\hat{B})^{2}}{\hat{\sigma}^{2} / \sum_{i=1}^{n}\left(x_{i}-\bar{x}\right)^{2}}\right)^{-\frac{(n-2)+1}{2}}
$$

Finally, the marginal posterior distribution of B is the Student's t-distribution with degrees of freedom (n-2), center $\hat{B}$, and scale parameter $\frac{\widehat{\sigma}^{2}}{\sum_{i=1}^{n}\left(x_{i}-\bar{x}\right)^{2}}$.

$$
B \mid y_{1}, \ldots, y_{n} \sim t\left(n-2, \hat{B}, \frac{\widehat{\sigma}^{2}}{s_{x x}}\right)
$$

\subsubsection{Marginal Posterior Distribution of A}

The marginal posterior distribution of $A$ is obtained by integrating $B$ and $\sigma^{2}$ out from the joint posterior distribution.

$$
\begin{aligned}
& p\left(A \mid y_{1}, \ldots, y_{n}\right)=\int_{0}^{\infty}\left(\int_{-\infty}^{\infty} P\left(A, B, \sigma^{2} \mid y_{1}, \ldots, y_{n}\right) d B\right) d \sigma^{2} \\
& \quad= \\
& \int_{0}^{\infty}\left(\int_{-\infty}^{\infty} \frac{1}{\left(\sigma^{2}\right)^{\frac{n+2}{2}}} \exp \left(-\frac{S S E+n[(A-\hat{A})+(B-\hat{B}) \bar{x}]^{2}+(B-\hat{B})^{2} S_{x x}}{2 \sigma^{2}}\right) d B\right) d \sigma^{2} \\
& \quad=\int_{0}^{\infty} p\left(A, \sigma^{2} \mid y_{1}, \ldots, y_{n}\right) d \sigma^{2}
\end{aligned}
$$

$$
\begin{aligned}
& p\left(A, \sigma^{2} \mid y_{1}, \ldots, y_{n}\right)= \\
& \int_{-\infty}^{\infty} \frac{1}{\left(\sigma^{2}\right)^{\frac{n+2}{2}}} \exp \left(-\frac{S S E+n[(A-\hat{A})+(B-\hat{B}) \bar{x}]^{2}+(B-\hat{B})^{2} S_{x x}}{2 \sigma^{2}}\right) d B \\
& \propto \frac{1}{\left(\sigma^{2}\right)^{\frac{n+1}{2}}} \exp \left(-\frac{S S E+\frac{(A-\widehat{A})^{2}}{\frac{1}{n}+\frac{\bar{x}^{2}}{\sum_{i=1}^{n}\left(x_{i}-\bar{x}\right)^{2}}}}{2 \sigma^{2}}\right)
\end{aligned}
$$

Considering $\emptyset=\frac{1}{\sigma^{2}}$, 


$$
\begin{aligned}
& p\left(A \mid y_{1}, \ldots, y_{n}\right)=\int_{0}^{\infty} p\left(A, \sigma^{2} \mid y_{1}, \ldots, y_{n}\right) d \sigma^{2} \\
& =\int_{0}^{\infty} \emptyset^{\frac{n-3}{2}} \exp \left(-\frac{S S E+\frac{(A-\widehat{A})^{2}}{\frac{1}{n}+\frac{\bar{x}^{2}}{\sum_{i=1}^{n}\left(x_{i}-\bar{x}\right)^{2}}}}{2} \emptyset\right) d \emptyset= \\
& \int_{0}^{\infty} p\left(A, \emptyset \mid y_{1}, \ldots, y_{n}\right) d \emptyset
\end{aligned}
$$

After integrating Eq. (22), the following equation is obtained:

$$
p\left(A \mid y_{1}, \ldots, y_{n}\right) \propto\left(1+\frac{1}{n-2} \times \frac{(A-\hat{A})^{2}}{\hat{\sigma}^{2}\left(\frac{1}{n}+\frac{\bar{x}^{2}}{\sum_{i=1}^{n}\left(x_{i}-\bar{x}\right)^{2}}\right)}\right)^{-\frac{(n-2)+1}{2}}
$$

Finally, the marginal posterior distribution of A is the Student's t-distribution with degrees of freedom (n-2), center $\hat{A}$, and scale parameter $\hat{\sigma}^{2}\left(\frac{1}{n}+\frac{\bar{x}^{2}}{\sum_{i=1}^{n}\left(x_{i}-\bar{x}\right)^{2}}\right)$.

$$
A \mid y_{1}, \ldots, y_{n} \sim t\left(n-2, \hat{A}, \hat{\sigma}^{2}\left(\frac{1}{n}+\frac{\bar{x}^{2}}{\sum_{i=1}^{n}\left(x_{i}-\bar{x}\right)^{2}}\right)\right)
$$

\subsubsection{Marginal Posterior Distribution of $\sigma^{2}$}

If the prior distribution of $\sigma^{2}, p\left(\sigma^{2}\right)$, proportional to $\frac{1}{\sigma^{2}}$, then the prior distribution of the precision $\phi\left(\varnothing=\frac{1}{\sigma^{2}}\right), p(\varnothing)$, is proportional to $\frac{1}{\emptyset}[36]$.

Therefore, the joint prior distribution is written as:

$$
p(A, B, \emptyset) \propto \frac{1}{\emptyset}
$$

As shown in Eq.(17), the joint distribution $p\left(B, \emptyset \mid y_{1}, \ldots, y_{n}\right)$ is written as:

$$
\begin{aligned}
& p\left(B, \emptyset \mid y_{1}, \ldots, y_{n}\right) \\
& \propto \emptyset^{\frac{n-3}{2}} \exp \left(-\frac{S S E+(B-\hat{B})^{2} \sum_{i=1}^{n}\left(x_{i}-\bar{x}\right)^{2}}{2} \emptyset\right)
\end{aligned}
$$

By integrating $p\left(B, \emptyset \mid y_{1}, \ldots, y_{n}\right)$ over $\mathrm{B}$, the following equation is obtained:

$$
p\left(\varnothing \mid y_{1}, \ldots, y_{n}\right) \propto \emptyset^{\frac{n-2}{2}-1} \exp \left(-\frac{S S E}{2} \emptyset\right)
$$

Finally, the marginal posterior distribution of $\varnothing$ is a Gamma distribution with a shape parameter $\frac{n-2}{2}$ and rate parameter $\frac{S S E}{2}$. 


$$
\emptyset \mid y_{1}, \ldots, y_{n} \sim \operatorname{Gamma}\left(\frac{n-2}{2}, \frac{S S E}{2}\right)
$$

Therefore, the updated $\sigma^{2}$ follows the inverse Gamma distribution.

\subsubsection{Joint posterior distribution}

Eq (26) can be reformulated as shown in Eq. (29).

$$
\begin{aligned}
& p\left(B, \emptyset \mid y_{1}, \ldots, y_{n}\right) \\
& \propto \emptyset^{\frac{n-3}{2}} \exp \left(-\frac{S S E+(B-\hat{B})^{2} \sum_{i=1}^{n}\left(x_{i}-\bar{x}\right)^{2}}{2} \emptyset\right) \\
& \propto\left[\emptyset^{\frac{1}{2}} \exp \left(-\frac{(B-\hat{B})^{2} \sum_{i=1}^{n}\left(x_{i}-\bar{x}\right)^{2}}{2} \emptyset\right)\right]\left[\emptyset^{\frac{n-2}{2}-1} \exp \left(-\frac{S S E}{2} \emptyset\right)\right]
\end{aligned}
$$

Therefore, the joint distribution $p\left(B, \varnothing \mid y_{1}, \ldots, y_{n}\right)$ can be viewed as the product of the posterior distribution of $B$ conditioning on $\phi$ and the posterior distribution of $\phi$. The first term, $\emptyset^{\frac{1}{2}} \exp \left(-\frac{(B-\hat{B})^{2} \sum_{i=1}^{n}\left(x_{i}-\bar{x}\right)^{2}}{2} \emptyset\right)$, is the Normal distribution with mean $\hat{B}$ and standard deviation $\frac{\sigma^{2}}{\sum_{i=1}^{n}\left(x_{i}-\bar{x}\right)^{2}}=\frac{\sigma^{2}}{S_{x x}}$. The second term, $\emptyset^{\frac{n-2}{2}-1} \exp \left(-\frac{S S E}{2} \emptyset\right)$, is the Gamma distribution of the precision $\phi$, or the inverse Gamma distribution of the variance $\sigma^{2}$.

$$
\begin{aligned}
& B \mid \sigma^{2}, \text { data } \sim \operatorname{Normal}\left(\hat{B}, \frac{\sigma^{2}}{S_{x x}}\right) \\
& 1 / \sigma^{2} \mid \text { data } \sim \operatorname{Gamma}\left(\frac{n-2}{2}, \frac{S E E}{2}\right)
\end{aligned}
$$

Therefore, the joint distribution of B and $\sigma^{2}$, under the reference prior, is a Normal-Gamma distribution on $\sigma^{2}$.

As shown in Eq. (22), the joint distribution $p\left(A, \emptyset \mid y_{1}, \ldots, y_{n}\right)$ is written as:

$$
\begin{aligned}
& p\left(A, \emptyset \mid y_{1}, \ldots, y_{n}\right) \propto \emptyset^{\frac{n-3}{2}} \exp \left(-\frac{S S E+\frac{(A-\widehat{A})^{2}}{\frac{1}{n}+\frac{\bar{x}^{2}}{\sum_{i=1}^{n}\left(x_{i}-\bar{x}\right)^{2}}}}{2} \emptyset\right) \\
& \propto\left[\emptyset^{\frac{1}{2}} \exp \left(-\frac{\left.\frac{(A-\widehat{A})^{2}}{\bar{x}^{2}+\frac{\bar{x}_{i=1}^{n}\left(x_{i}-\bar{x}\right)^{2}}{2}} \emptyset\right)\left[\emptyset^{\frac{n-2}{2}-1} \exp \left(-\frac{S S E}{2} \emptyset\right)\right]}{}\right)\right]
\end{aligned}
$$

As shown in Eq. (32), the joint distribution $p\left(A, \varnothing \mid y_{1}, \ldots, y_{n}\right)$ can be viewed as the product of the posterior distribution of A conditioning on $\phi$ and the posterior distribution of $\phi$. The first term, $\emptyset^{\frac{1}{2}} \exp \left(-\frac{\frac{(A-\widehat{A})^{2}}{\frac{1}{n}+\frac{\bar{x}^{2}}{\sum_{i=1}^{n}\left(x_{i}-\bar{x}\right)^{2}}}}{2} \emptyset\right)$, is the Normal distribution with mean $\hat{A}$ and standard 
deviation $\sigma^{2}\left(\frac{1}{n}+\frac{\bar{x}^{2}}{\sum_{i=1}^{n}\left(x_{i}-\bar{x}\right)^{2}}\right)=\sigma^{2}\left(\frac{1}{n}+\frac{\bar{x}^{2}}{S_{x x}}\right)$. The second term, $\emptyset^{\frac{n-2}{2}-1} \exp \left(-\frac{S S E}{2} \emptyset\right)$, is the Gamma distribution of the precision $\phi$, or the inverse Gamma distribution of the variance $\sigma^{2}$.

$$
\begin{aligned}
& A \mid \sigma^{2}, \text { data } \sim \operatorname{Normal}\left(\hat{A}, \sigma^{2}\left(\frac{1}{n}+\frac{\bar{x}^{2}}{S_{x x}}\right)\right) \\
& 1 / \sigma^{2} \mid \text { data } \sim \operatorname{Gamma}\left(\frac{n-2}{2}, \frac{S E E}{2}\right)
\end{aligned}
$$

Therefore, the joint distribution of $\mathrm{A}$ and $\sigma^{2}$, under the reference prior, is a Normal-Gamma distribution on $\sigma^{2}$.

\subsection{Methods of evaluation}

One of the problems with the comparison of creep data with a model's prediction is the increasing divergence and spread of data with time. Consequently, the divergence and spread are a measure of the limitation of the model's capabilities and variability in the experimental data The calculation of a coefficient of variation or standard error of regression normalized by the data centroid are from the methods commonly used for determining the deviation of a model from the data [18]. Several methods have been used for the evaluation of the accuracy of models to predict experimental data. In this study, Bazant and Panula (BP) coefficient of variation [37], Comité Européen du Béton (CEB) coefficient of variation [38] and Gardner coefficient of variation [39] are used.

\subsubsection{BP coefficient of variation $\left(\overline{\boldsymbol{w}}_{\boldsymbol{B P}} \%\right)$ method}

A coefficient $\bar{w}_{B P}$ is determined for the data set [37]. Data points in each logarithmic decade, 0 to 9.9 days, 10 to 99.9 days, and so on, are considered as one group. Weight is assigned to each data point based on the decade in which it falls and the number of data points in that particular decade.

\subsubsection{CEB coefficient of variation $\left(V_{C E B}\right)$}

The CEB statistical indicators were suggested by Muller and Hilsdorf [38]. The indicators are calculated in six-time ranges: 0 to 10 days, 11 to 100 days, 101 to 365 days, 366 to 730 days, 731 to 1095 days, and above 1095 . The final $V_{\text {СЕB }}$ value is the root mean square (RMS) of the six interval values.

\subsubsection{The Gardner coefficient of variation $\left(\boldsymbol{\omega}_{G}\right)$}

The mean observed value and RMS of the difference between calculated and observed values are calculated in half-logarithmic time intervals: 3 to 9.9 days, 10 to 31.5 days, 31.6 to 99 days, 100 to 315 days, 316 to 999 days, 1000 to 3159, and above 3160 days. Then, the average values and RMSs are calculated without regard to the number of observations in each half-decade. Finally, the Gardner coefficient of variation, $\omega_{G}$, is obtained by dividing the average RMS normalized by the average value [39].

\section{Results and discussion}

179 experiments performed under various conditions with 1488 readings having loading age equal or greater to 700 days ( $t_{0} \geq 700$ days) are chosen from the NU database for this study. The creep coefficient is calculated according to the EC2 model [19] for each observation. Finally, the linear regression presented in Eq. (7) is applied for these 1488 readings. 
Fig. 2 shows the graph of the residuals obtained for the EC2 model plotted against the creep coefficient. Positive residuals mean that the model underestimates the creep coefficient while negative values indicate that the model overestimates the creep coefficient. An accurate creep coefficient prediction is illustrated by residuals close to zero. As shown in Fig. 2, the EC2 model may underestimate or overestimate the creep coefficient for a creep coefficient value less than 4; however, for higher values of the creep coefficient, the EC2 model underestimates the creep coefficient, and the residual magnitude is very high underlining the inadequacy of the EC2 in creep coefficient prediction.

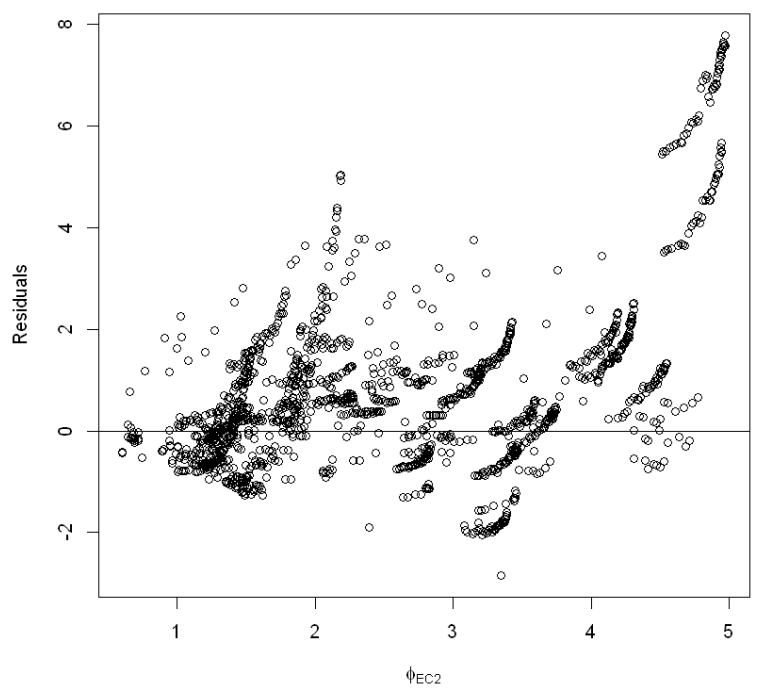

Fig. 2 Plot of creep coefficient residuals for the 1488 readings

As the EC2 model calculates the creep coefficient based on the value of the compressive strength (i.e. less or greater than $35 \mathrm{MPa}$ ), the data is first divided into two categories: group1 and group 2. Group 1 includes observations with compressive strength less or equal to $35 \mathrm{MPa}$. Group 2 is formed from observations having a compressive strength greater than $35 \mathrm{MPa}$. The goal is to find out in which combination of parameters the EC2 model underestimates or overestimates the creep coefficient. Further investigation and exploration of the data are made to obtain more precise results for the correction coefficients values and led to the division of the data into six groups (see Table 1) based on the underestimation and overestimation of the EC2 model.

Table 1. Properties of each group

\begin{tabular}{cc}
\hline Group a & $\mathrm{f}_{\mathrm{cm}} \leq 35 \mathrm{MPa}$ and $\frac{\sigma}{f_{c m\left(t_{0}\right)}}<0.3$ \\
Group b & $\mathrm{f}_{\mathrm{cm}} \leq 33 \mathrm{MPa}$ and $\frac{\sigma}{f_{c m\left(t_{0}\right)}} \geq 0.3$ \\
Group c & $33 \mathrm{MPa}<\mathrm{f}_{\mathrm{cm}} \leq 35 \mathrm{MPa}$ and $\frac{\sigma}{f_{c m\left(t_{0}\right)}} \geq 0.3$ \\
Group d & $35 \mathrm{MPa}<\mathrm{f}_{\mathrm{cm}}<45 \mathrm{MPa}$ and $\mathrm{RH}<80 \%$ \\
Group e & $\mathrm{f}_{\mathrm{cm}} \geq 45 \mathrm{MPa}$ and $\mathrm{RH}<80 \%$ \\
Group f & $\mathrm{f}_{\mathrm{cm}} \geq 35 \mathrm{MPa}$ and $\mathrm{RH} \geq 80 \%$ \\
\hline
\end{tabular}


Table 1 shows the properties of each of the six groups. Group 1 is mainly divided according to the value of the ratio of sustained load to compressive strength at loading age $\left(\frac{\sigma}{f_{c m\left(t_{0}\right)}}\right)$. Group a includes the observations of group 1 with $\frac{\sigma}{f_{c m\left(t_{0}\right)}}$ less than 0.3. Observations where $\frac{\sigma}{f_{c m\left(t_{0}\right)}}$ equal to or greater than 0.3 are divided into group b and group $\mathrm{c}$ depending on the value of compressive strength (i.e. less or greater than $33 \mathrm{MPa}$ ). For group 2, observations are primarily divided according to the relative humidity (RH). For RH value less than $80 \%$, the observations of group 2 with compressive strength less than $45 \mathrm{MPa}$ and equal to or greater than $45 \mathrm{MPa}$ are found in groups $\mathrm{d}$ and e, respectively. Group $\mathrm{f}$ includes observations from group 2 having relative humidity equal to or greater than $80 \%$. The division is thus made according to the compressive strength $\left(\mathrm{f}_{\mathrm{cm}}\right)$, ratio of sustained load to compressive strength at loading age $\left(\frac{\sigma}{f_{c m\left(t_{0}\right)}}\right)$ and relative humidity $(\mathrm{RH})$. The effect of loading age $\left(t_{0}\right)$ is implicitly considered in the ratio of sustained load to compressive strength at loading age $\left(\frac{\sigma}{f_{c m\left(t_{0}\right)}}\right)$ as the loading age greatly influences the compressive strength. Indeed, this division fits the results of studies found in the literature according to the most important factors affecting creep $[12,40]$, where compressive strength, relative humidity, sustained load and loading age were the highest factors affecting creep.

Based on the data division shown in Table 1, Fig. 3 clearly shows that the EC2 model underestimates the creep coefficient in the case of groups $b, d$ and e, while it overestimates the creep coefficient in the case of groups a and c.

In order to apply the BLR, the error $\epsilon_{i}$ should be normally distributed with zero mean and constant variance $\sigma^{2}$. Fig. 4 shows the histogram of the error $\epsilon_{i}$, which is the difference between the observed value and the predicted value, for the six groups. The Shapiro-Wilk test is applied and the p-value for the six groups is greater than 0.05 ; thus, the normality of the error $\epsilon_{i}$ is verified and Bayesian linear regression can be applied. Therefore, the random variable of each response $\mathrm{y}_{\mathrm{i}}$, conditioning on the observed data $\mathrm{x}_{\mathrm{i}}$ and the parameters $A, B$ and $\sigma^{2}$, is also normally distributed.

By considering the likelihood distribution (see Eq. (9)) and the reference prior (see Eq. (12)), the marginal distributions of $A, B$ and $\sigma^{2}$ are calculated as mentioned in section 2 . The correction coefficients, $A$ and B, and their $95 \%$ credible interval (CI) are calculated and listed in Table 2. For a 95\% CI, the value of interest (i.e. A or B) lies with a $95 \%$ probability in the interval. For example, there is a $95 \%$ chance that the correction coefficient B will increase by $1.09 \%$ up to $1.26 \%$ for each additional increase in the EC2 creep coefficient in group a. In groups a and c where the EC2 model overestimates the creep coefficient (Fig. 3 ), the values of $A$ are 0.67 and 0.58 for groups a and c, respectively, and the values of $B$ are 1.18 and 1.02, respectively. The values of $A$ and $B$ in groups $b, d$ and e are greater than one as the EC2 model underestimates the creep coefficient in these groups. The values of A and $\mathrm{B}$ in group $\mathrm{f}$ are 1.03 and 0.87 , respectively. Fig. 5 shows the residuals plots of the six groups after the implementation of the correction coefficients into the EC2 creep model. Fig. 6 shows the $x-y$ scatter plots of the six groups with the fitted line. The $x$-axis represents the natural logarithm of the EC2 creep coefficient and the y-axis represents the natural logarithm of the actual creep coefficient in the Northwestern University database. 
Table 2. Values of the correction coefficients A and B and their $95 \%$ credible intervals

\begin{tabular}{ccccccc}
\hline & Group a & Group b & Group c & Group d & Group e & Group f \\
\hline A & 0.67 & 1.43 & 0.58 & 1.13 & 1.20 & 1.03 \\
95\%CI of A [0.63;0.72] & {$[1.34 ; 1.55]$} & {$[0.50 ; 0.68]$} & {$[1.01 ; 1.28]$} & {$[1.06 ; 1.36]$} & {$[0.87 ; 1.22]$} \\
B & 1.18 & 1.02 & 1.28 & 1.14 & 1.36 & 0.54 \\
95\%CI of B [1.09;1.26] & {$[0.95 ; 1.08]$} & {$[1.09 ; 1.47]$} & {$[1.01 ; 1.26]$} & {$[1.18 ; 1.55]$} & {$[-0.09 ; 1.16]$} \\
\hline
\end{tabular}

Table 3 shows the values of the statistical indicators before and after the implementation of the correction coefficient in the EC2 model (Eq. 2). These statistical indicators are calculated to verify the accuracy and effectiveness of the proposed improvement and modification of the EC2 model. As indicated in Table 3, the implementation of the correction coefficients, $\mathrm{A}$ and $\mathrm{B}$, provides a significant improvement of the results where $\bar{w}_{B P}, V_{C E B}$, and $\omega_{G}$ decreased by $24 \%, 24 \%$, and $26 \%$, respectively; therefore, the updated model proves to be an effective solution to improve the prediction of creep coefficient.

Table 3. Statistical indicators of the EC2 model and the updated EC2 model

\begin{tabular}{cccc}
\hline & $\bar{w}_{B P}$ & $V_{C E B}$ & $\omega_{G}$ \\
\hline Target value & 0 & 0 & 0 \\
EC2 model & 0.58 & 0.50 & 0.57 \\
Updated EC2 model & 0.44 & 0.38 & 0.42 \\
\hline
\end{tabular}



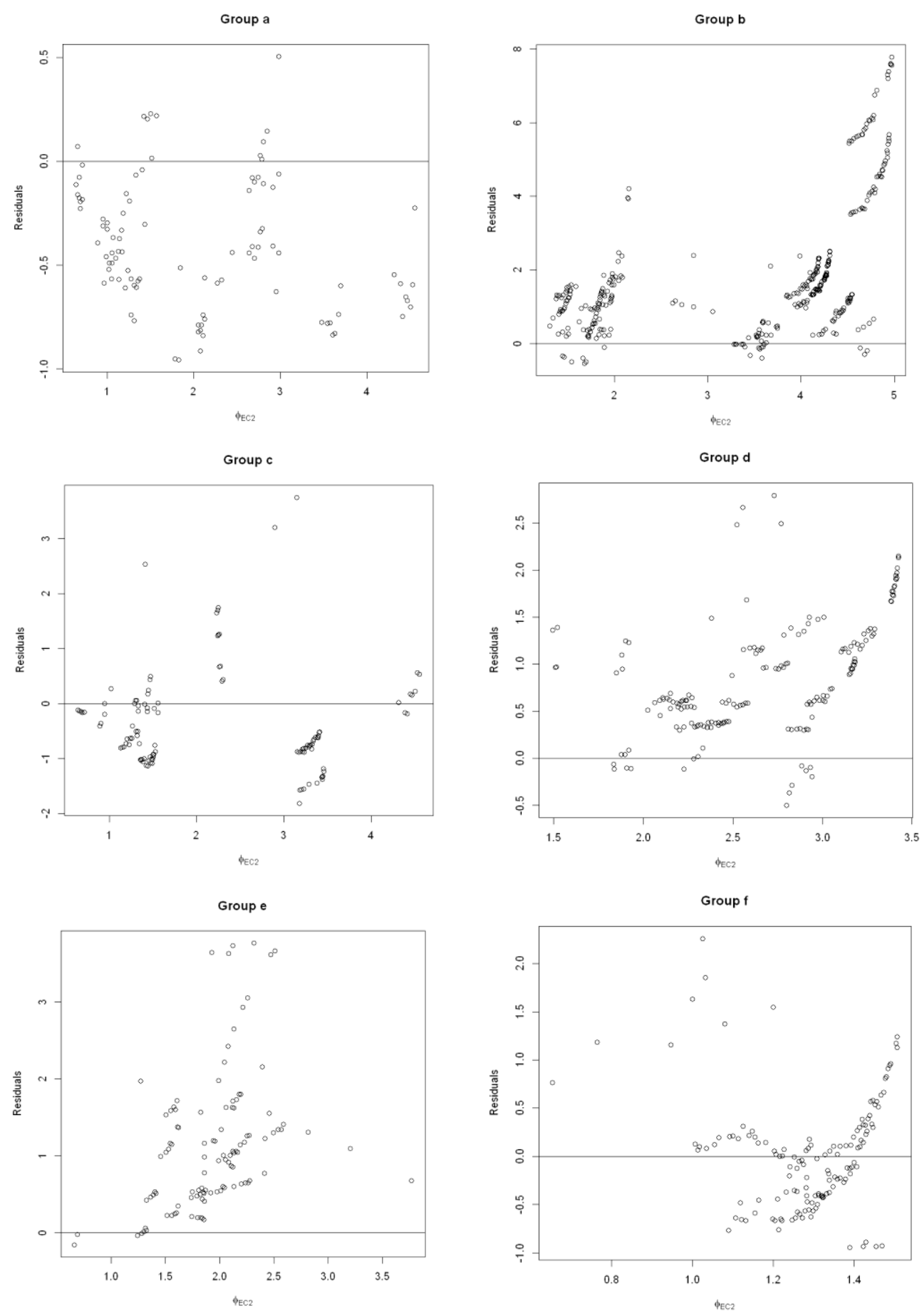

Fig. 3 Plot of creep coefficient residuals for the six groups (according to the EC2 model) 
Group a (p-value $=0.059)$

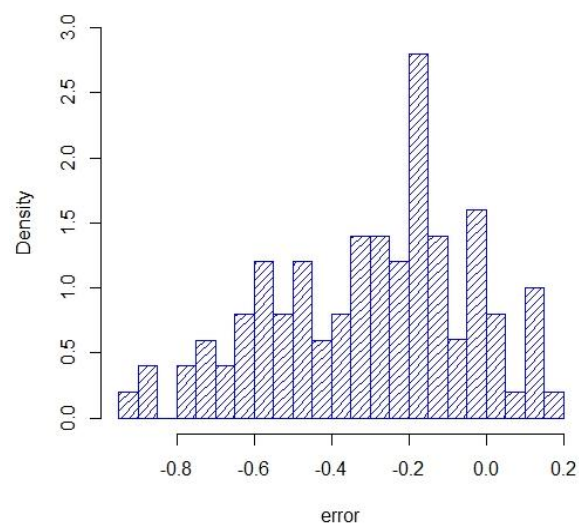

Group c $(p-$ value $=0.061)$

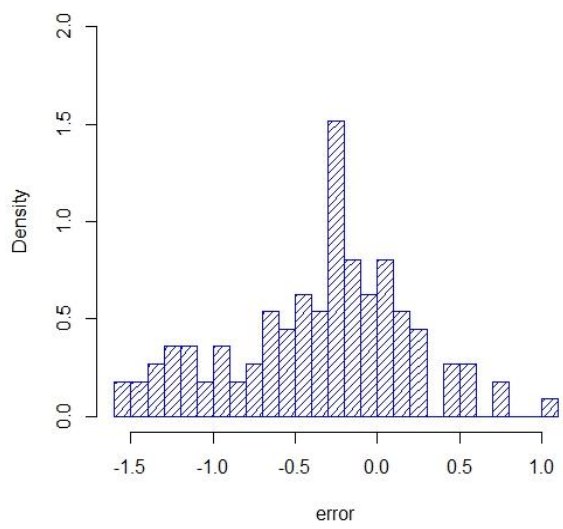

Group e (p-value $=0.063)$

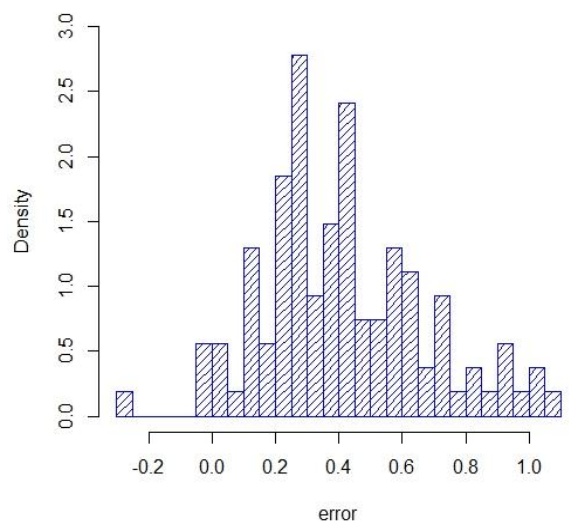

Group b (p-value $=0.054)$

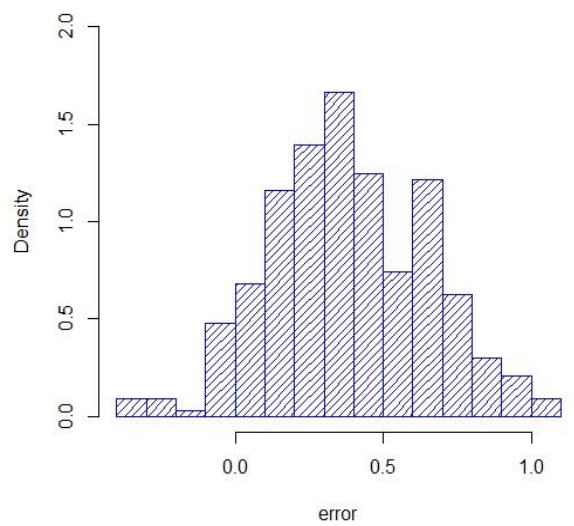

Group d (p-value $=0.06)$

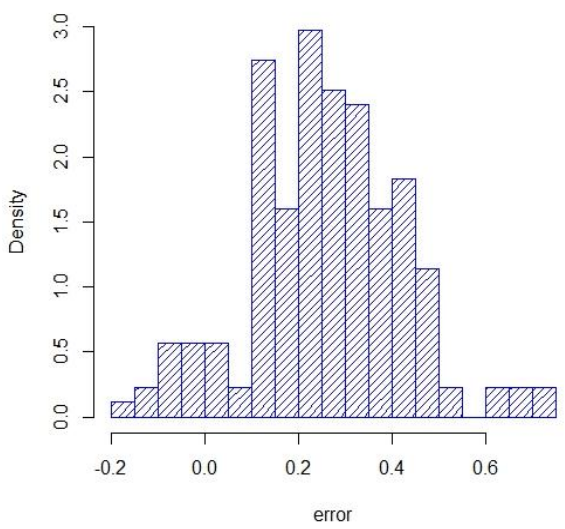

Group $f(p-v a l u e=0.064)$

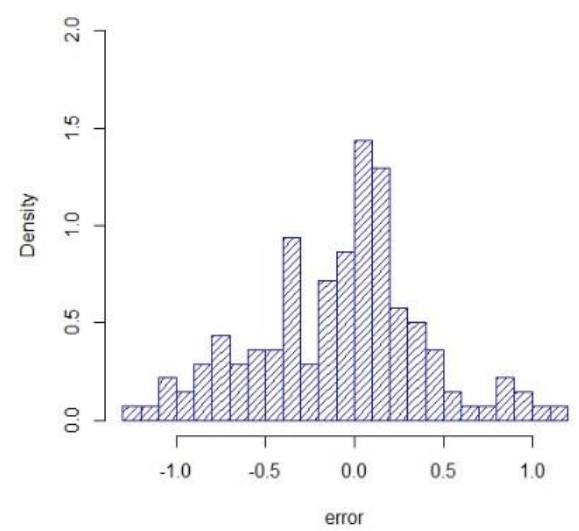

Fig. 4 Histogram of the error $\epsilon_{i}$ for the six groups with the p-value of the Shapiro-Wilk test 

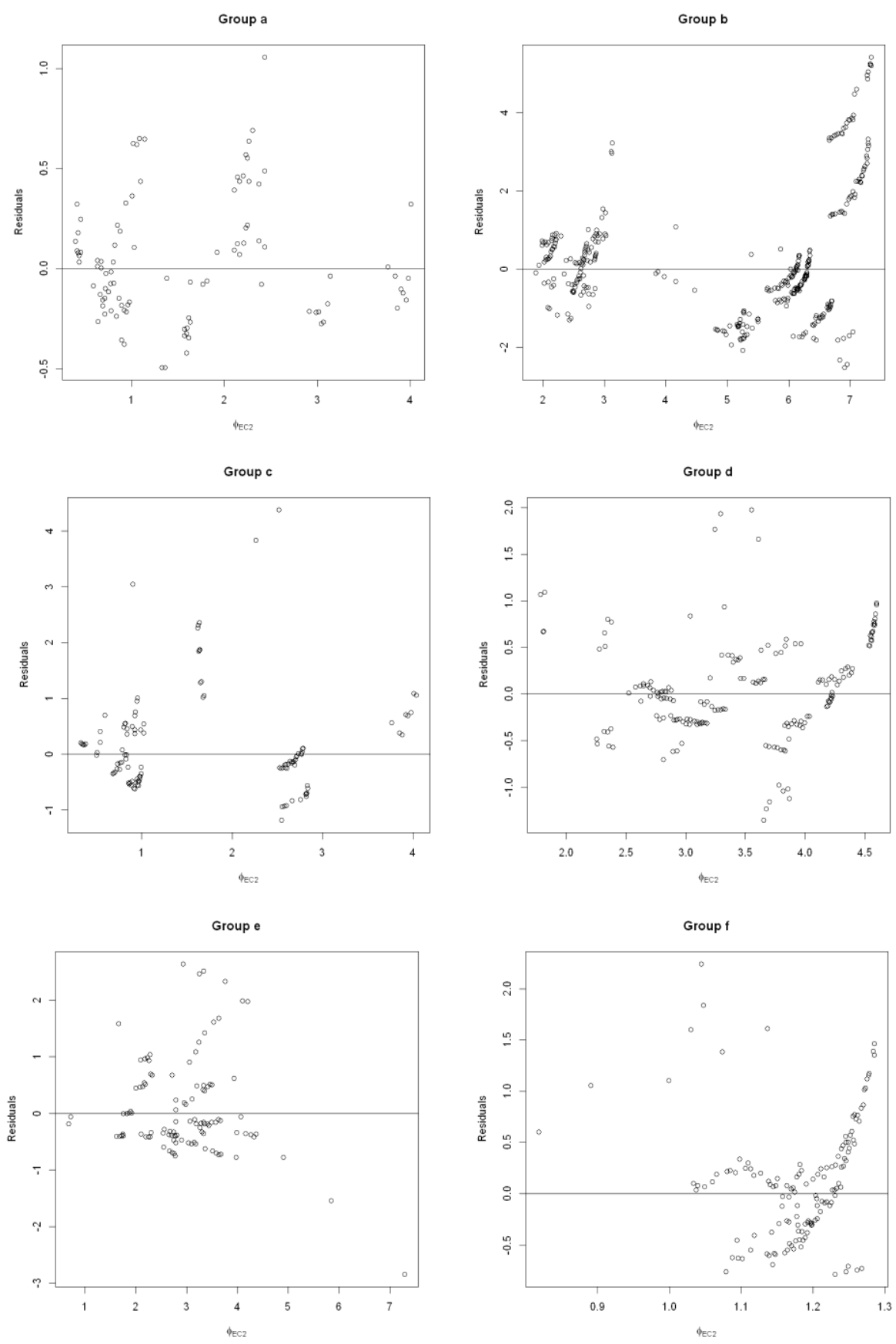

Fig. 5 Plot of creep coefficient residuals for the six groups (according to the updated EC2 creep model) 

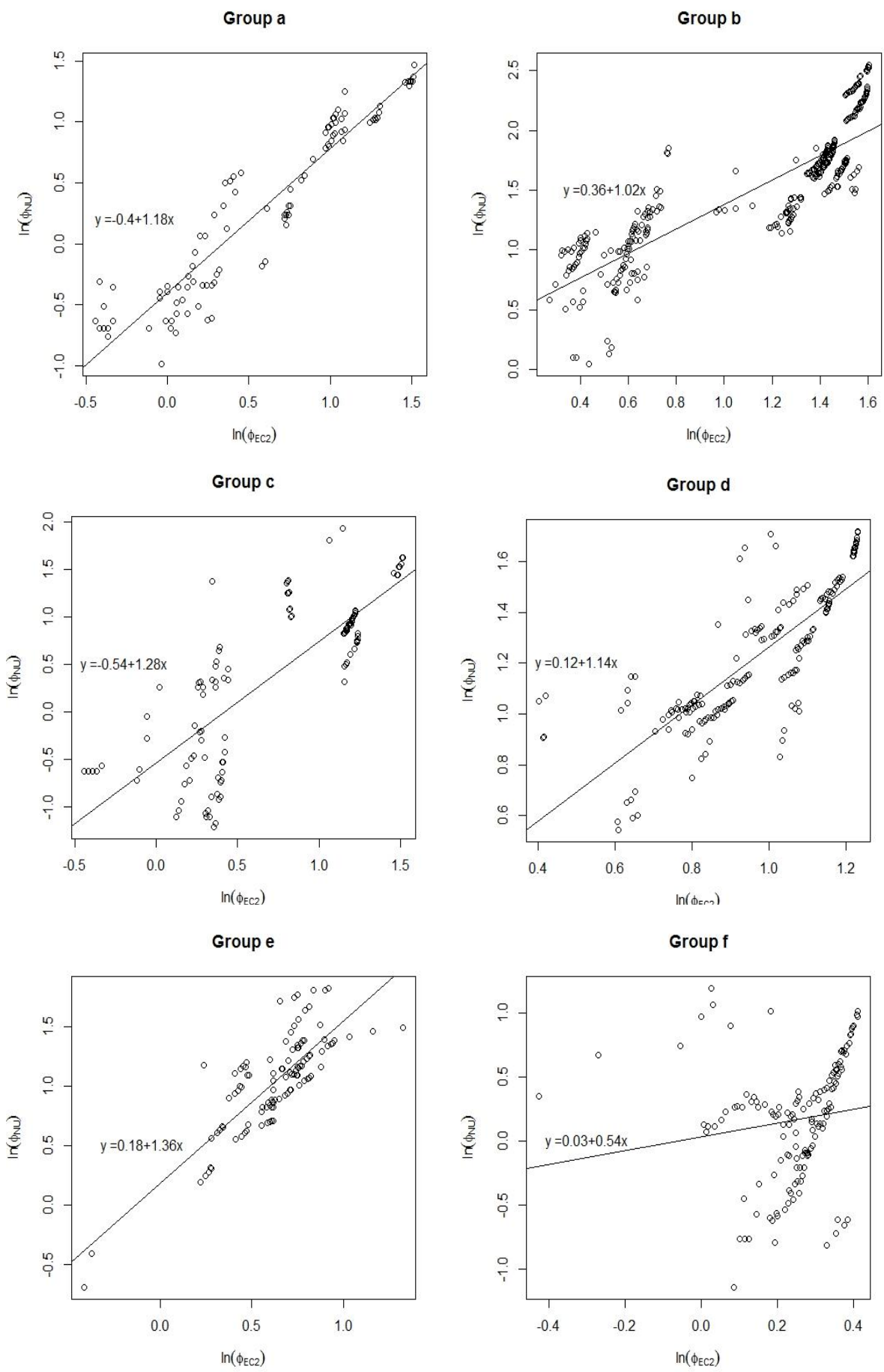

Fig. 6 Plots of the natural logarithm of the EC2 creep coefficient versus the natural logarithm of the actual creep coefficient for the six group 


\section{Conclusion}

Creep can affect the structural behavior by violating the service limit states, losing the prestressing forces, or redistributing the stress in concrete members. For that, engineers should accurately predict creep. Therefore, this paper aims to update the EC2 creep coefficient prediction by implementing correction coefficients into the model. The Northwestern University dataset was used in this study, which contains a large number of creep tests that are performed using different concrete mix compositions and under various environmental conditions such as aggregate-cement ratio, water-cement ratio, concrete compressive strength, cement type, effective thickness, loading age, sustained stress over the compressive strength at loading age, temperature, and relative humidity.

Since Bayesian-type inferences are considered as suitable tools to revise and update design codes, the correction coefficients were calculated using Bayesian linear regression. An approach based on Bayesian linear regression was developed in this study to define a methodology for updating the EC2 model. This methodology allows determining the correction coefficients that must be introduced into the EC2 creep coefficient model.

A total of 1488 readings of creep coefficient, with loading age greater than 700 days, were extracted from the NU database. The data was then explored and divided into six groups according to the compressive strength, sustained stress over the compressive strength at loading age and relative humidity. Next, the normality of the data in the six groups was checked using the Shapiro-Wilk test. Finally, the correction coefficients were calculated for the different groups.

Statistical indicators (BP coefficient of variation, CEB coefficient of variation and Gardner coefficient of variation) have decreased by $24 \%, 24 \%$, and $26 \%$, respectively, after the implementation of the correction coefficients in the EC2 model. Therefore, the presented approach has proven to be an effective solution for improving the creep coefficient prediction. The adoption of the updated model would improve the long-term serviceability of structures subjected to time-dependent creep strains.

\section{References}

[1] Sankaya H, Susurluk G. Effect of polypropylene fiber addition on thermal and mechanical properties of concrete. Research on Engineering Structures \& Materials, 2019;5(1):1-12. https://doi.org/10.17515/resm2018.72ma1109

[2] Palanci M. Yield response prediction of unsymmetrically reinforced concrete rectangular beams. Research on Engineering Structures \& Materials, 2020;6(2):10518. https://doi.org/10.17515/resm2019.141st0802

[3] Seranaj A, Elezi E, Seranaj A. Structural optimization of reinforced concrete spatial structures with different structural openings and forms. Research on Engineering $\begin{array}{llll}\text { Structures } \quad \& \quad \text { Materials, } & \text { 2018;4(2):79-89. }\end{array}$ https://doi.org/10.17515/resm2016.79st0726

[4] Yaghi K, Hammoud H. Strength evaluation of a fire damaged concrete slab : combined correlation approach. Research on Engineering Structures \& Materials, 2018;4(4):231 40. https://doi.org/10.17515/resm2018.40me0127

[5] Raphael W, Zgheib E, Chateauneuf A. Experimental investigations and sensitivity analysis to explain the large creep of concrete deformations in the bridge of Cheviré. Case Studies in Construction Materials, 2018;9:e00176. https://doi.org/10.1016/j.cscm.2018.e00176

[6] Daou H, Abou Salha W, Raphael W, Chateauneuf A. Explanation of the collapse of Terminal 2E at Roissy-CDG Airport by nonlinear deterministic and reliability analyses. 
Case Studies in Construction Materials, 2019;10. https://doi.org/10.1016/j.cscm.2019.e00222

[7] Raphael W, Faddoul R, Feghaly R, Chateauneuf A. Analysis of Roissy Airport Terminal 2E collapse using deterministic and reliability assessments. Engineering Failure Analysis, 2012;20:1-8. https://doi.org/10.1016/j.engfailanal.2011.10.001

[8] Daou H, Raphael W. Comparison between Various Creep Calculation Methods for the Time-dependent Analysis of Terminal 2E at Roissy. Jordanian Journal of Civil Engineering, 2021;15(1):64-76.

[9] Chateauneuf A, Raphael W, Rostand JB, Pitti M. Reliability of prestressed concrete structures considering creep models. Structure and Infrastructure Engineering: Maintenance, Management, Life-Cycle Design and Performance, 2014;10:12:1595-605. https://doi.org/10.1080/15732479.2013.835831

[10]Daou H, Raphael W, Chateauneuf A, Geara F. Probabilistic Assessment of Structural Safety of Complex Structures - Application to Terminal 2E at Roissy, CDG Airport. Procedia Structural Integrity, 2019;22:17-24. https://doi.org/10.1016/i.prostr.2020.01.003

[11] Daou H, Raphael W. Investigation of the Significance of Factors Affecting Long-Term Creep of Concrete using Screening Designs. IOP Conferences Series: Materials Science and Engineering, 2020;809. https://doi.org/10.1088/1757-899X/809/1/012016

[12] Daou H, Rapahel W. Identifying the Weight of Factors Affecting Creep of Concrete Using Factorial ANOVA. Key Engineering Materials, 2021;872:21-5. https://doi.org/10.4028/www.scientific.net/KEM.872.21

[13] Saad L, Chateauneuf A, Raphael W. Robust formulation for Reliability-based design optimization of structures. Structural and Multidisciplinary Optimization, 2018;57:2233-48. https://doi.org/10.1007/s00158-017-1853-7

[14] Gan Y, Romero Rodriguez C, Zhang H, Schlangen E, van Breugel K, Šavija B. Modeling of microstructural effects on the creep of hardened cement paste using an experimentally informed lattice model. Computer-Aided Civil and Infrastructure Engineering, 2021. https://doi.org/10.1111/mice.12659

[15] Zheng Z, Hu D, Liu P, Sha F, Liu L, Yu Z. Considering the effect of the randomness of concrete strength and relative humidity on concrete creep. Structural Concrete, 2020;1-15. https://doi.org/10.1002/suco.202000139

[16] Topçu İB, Uzunömeroğlu A. Experimental investigation of utilizing chemical additives and new generation corrosion inhibitors on reinforced concrete. Research on $\begin{array}{llll}\text { Engineering } & \text { Structures } & \text { \& } & \text { Materials, }\end{array}$ https://doi.org/10.17515/resm2020.214st0929

[17] Fares AM. The impact of RC shear wall openings at the lateral stiffness of the cantilever shear walls. Research on Engineering Structures \& Materials, 2020. https://doi.org/10.17515/resm2020.208st0816

[18] ACI Committee 209. Guide for Modeling and Calculating Shrinkage and Creep in Concrete Structures. ACI 209.2R-08. American Concrete Institute Report 209.2R-08, Farmington Hills, 2008.

[19] CEN. EN 1992-1-1, Eurocode 2: Design of concrete structures - Part 1-1 : General rules and rules for buildings, 2004.

[20] Bažant ZP, Baweja S. Creep and shrinkage prediction model for analysis and design of concrete structures: Model B3, A. Al-Manaseer, editor. Adam Neville Symposium: Creep and Shrinkage Structural Design Effect, 2000.

[21] CEB. Structural Concrete-Textbook on Behaviour, Design and Performance. Updated Knowledge of the CEBI FIP Model Code 1990. fib Bull 2, 1999;2:37-52.

[22] Gardner NJ. Design provisions of shrinkage and creep of concrete. Al-Manaseer A, editor. Adam Neville Symposium: Creep and Shrinkage Structural Design Effect. 2000;101-4. 
[23] Raphael W, Faddoul R, Geara F, Chateauneuf A. Improvements to the Eurocode 2 shrinkage model for concrete using a large experimental database. Structural Concrete, 2012;13(3):174-81. https://doi.org/10.1002/suco.201100029

[24] Raphael W, Faddoul R, Selouan DE-A, Chateauneuf A. Information-based formulation for Bayesian updating of the Eurocode 2 creep model. Structural Concrete, 2009;10(2):1-55. https://doi.org/10.1680/stco.2009.10.2.55

[25] Faddoul R, Soubra A, Raphael W, Chateauneuf A. Extension of dynamic programming models for management optimisation from single structure to multi-structures level. Structure and Infrastructure Engineering: Maintenance, Management, Life-Cycle Design and Performance, 2013;9:5:432-47. https://doi.org/10.1080/15732479.2011.557082

[26] Faddoul R, Raphael W, Chateauneuf A. Maintenance optimization of series systems subject to reliability constraints. Reliability Engineering and System Safety, 2018;180:179-88. https://doi.org/10.1016/j.ress.2018.07.016

[27] Faddoul R, Raphael W, Soubra A-H, Chateauneuf A. Incorporating Bayesian Networks in Markov Decision Processes. Journal of Infrastructure Systems, 2013;19(4):415-24. https://doi.org/10.1061/(ASCE)IS.1943-555X.0000134

[28] Rossi PE, Allenby GM, McCulloch R. Bayesian Statistics and Marketing. Bayesian Statistics and Marketing. West Sussex, England: John Wiley \& Sons, 2005. https://doi.org/10.1002/0470863692

[29] Jose M. Bernardo, Adrian F. M. Smith. Bayesian Theory. West Sussex, England: John Wiley \& Sons, 2000.

[30] Robert CP. The Bayesian Choice. New York, USA: Springer, 2007.

[31] Aladejare AE, Idris MA. Performance analysis of empirical models for predicting rock mass deformation modulus using regression and Bayesian methods. Journal of Rock Mechanics and Geotechnical Engineering, 2020;12:1263-71. https://doi.org/10.1016/j.jrmge.2020.03.007

[32] Ghosh S, Chakraborty S. Seismic fragility analysis of structures based on Bayesian linear regression demand models. Probabilistic Engineering Mechanics, 2020;61:103081. https://doi.org/10.1016/j.probengmech.2020.103081

[33] Cheng K, Lu Z. Adaptive Bayesian support vector regression model for structural reliability analysis. Reliability Engineering and System Safety, 2020;107286. https://doi.org/10.1016/j.ress.2020.107286

[34] Zhao H, Chen B, Li S, Li Z, Zhu C. Updating the models and uncertainty of mechanical parameters for rock tunnels using Bayesian inference. Geoscience Frontiers, 2021;12:101198. https://doi.org/10.1016/j.gsf.2021.101198

[35] Akaike H. A New Look at the Statistical Model Identification. IEEE Trans Automat Contr. 1974;19(6):716-23. https://doi.org/10.1109/TAC.1974.1100705

[36] Clyde M, Cetinkaya-Rundel M, Rundel C, Banks D, Chai C, Huang L. An Introduction to Bayesian Thinking A Companion to the Statistics with R Course, 2020.

[37] Bažant ZP, Panula L. Practical prediction of time-dependent deformations of concrete. Part II: Basic creep. Matériaux et Constructions, 1978;11:317-28. https://doi.org/10.1007/BF02473873

[38] Muller HS, Hilsdorf HK. Evaluation of the time-dependent behavior of concrete, summary report on the work of general task group 9. CEB Bull d'Information. 1990;199.

[39] Gardner NJ. Comparison of prediction provisions for drying shrinkage and creep of normal-strength concretes. Canadian Journal of Civil Engineering, 2004;31(5):767-75. https://doi.org/10.1139/104-046

[40] Adam I, Taha MMR. Identifying the Significance of Factors Affecting Creep of Concrete: A Probabilistic Analysis of RILEM Database. International Journal of Concrete Structures and Materials, 2011;5(2):97-111. https://doi.org/10.4334/IJCSM.2011.5.2.97 